\title{
A EDUCAÇÃO VISUAL NA TELEVISÃO VISTA COMO EDUCAÇÃO CULTURAL, POLÍTICA E ESTÉTICA ${ }^{1}$
}

\section{Milton José de Almeida}

\section{Resumo}

Estudos sobre a educação visual e a memória produzidas pelas imagens e sons da televisão e do cinema são importantes para entender de maneira mais ampla a educação cultural, científica e política das pessoas, e não somente aquela escolar ou escolar-universitária, pois, hoje, a maior parte das populações vê o real naturalizado, reproduzido pela fotografia, pela cinematografia, pela videografia, como verdadeira representação visual do real, com a qual opinam, produzem verdades e agem tanto no mundo cotidiano como no intelectual, acadêmico.

\section{Palavras-chave}

Educação, Memória, Imagens, Sons, Cinema, Televisão

\begin{abstract}
Studies about the visual education and the memory produced the images and sounds of television and of the movies are important for understanding in a wider way the cultural, scientific and political education of the people in society, and not only that of the school or university, because today most of the populations sees the naturalized Real, reproduced by photographs, movies, videos, as the true visual representation of the Real, with which they speak about, produce truths and act so much in the daily world as in the intellectual and academic world.
\end{abstract}

\section{Key-words}

Education, Memory, Images, Sounds, Movies, Television

\footnotetext{
${ }^{1}$ Artigo também publicado na Pro-Posições, v.10, n.2, maio 1999, com o mesmo enfoque, mas com titulo diferente.
} 


\section{INTRODUÇÃO}

As imagens do cinema e da televisão governam a educação visual contemporânea e, em estética e política, reconstroem, à sua maneira, a história de homens e sociedades. São imagens e sons da língua "escrita" da realidade, artefatos da memória, habitados por imagens em movimento. Por serem discursos em língua da realidade trazem dela o inconcluso, a ambigüidade, a mistura, o conflito, a história. Participam da mitologia do poder político e econômico, em suas versões massificadas, populares. Também, não tão populares, participam em diferentes graus, da mitologia futura em estética crítica quando trazem em seu discurso o inconcluso, a ambigüidade, a mistura, o conflito, não só da história e do real, como também o conflito ideológico-estético do aparato técnico da sua linguagem: câmeras, lentes, roteiros, cenografia, planos, sequiências, edição., etc. Assim, suas imagens e sons em movimento, mesmo captadas pelo olho unívoco e objetivo da câmera, escapam, em parte, pelo olhar humano do espectador, que as vê em tensão e não somente em afirmação.

O conhecimento visual de inúmeras outras representações já vistas participam da educação cultural, estética e política e da educação da memória ${ }^{2}$. Uma educação

\footnotetext{
${ }^{2}$ Poucos sabem que os gregos, inventores de tantas artes, inventaram também uma arte da memória que, como todas as artes, foi transmitida a Roma e de lá passou para a tradição européia. Esta arte procura fixar as recordações através da técnica de imprimir na memória "lugares" e "imagens". Catalogada, quase sempre, como "mnemotécnica", nos tempos modernos parece, pelo contrário, um ramo secundário da atividade humana. Mas na época precedente à invenção da imprensa, uma memória bem adestrada era de importância vital; e a manipulação das imagens na memória deve sempre, em alguma medida, envolver a psique como um todo. Além do mais, uma arte que use para os seus "lugares" de memória a arquitetura
}

visual cuja configuração estética é uma configuração política e cultural e uma forma complexa do viver cultural e social permeado de representações visuais em que percepção - ver as imagens, identificar com anteriores e imaginação ligar mentalmente uma à outra e ao assunto e, ao mesmo tempo, imaginar os elementos que as constituem, entender as proporções (e as desproporções) e as pessoas e coisas que nelas aparecem para percebê-las como uma história. Estamos dentro de um processo de educação cultural da inteligência visual. Uma arte que, em forma plástica, dá visibilidade estética a um momento social, político.

As imagens do cinema e da televisão, feitas para sessões ou programas, nos quais as divergências estético-políticas podem ter seu pequeno público ou em programas populares, nos quais a homologação estético-política é celebrada para multidões de espectadores, é uma produção material coletiva e uma

contemporânea e para as suas "imagens" a arte figurativa contemporânea, deve ter, como as outras artes, um período clássico, um gótico e um renascimental. Se bem que o aspecto mnemotécnico da arte estivesse sempre presente tanto na antigüidade como nas épocas sucessivas, e constituísse a base factual da sua investigação, um estudo que aborde esta arte deve estender-se muito além da história das suas técnicas. Mnemosine, diziam os gregos, é a mãe das Musas; a história da educação desta que é a mais fundamental e fugitiva faculdade humana está destinada a imergir em águas profundas. Frances $A$. Yates, L'Arte della memoria, p. xxviii

${ }^{3}$ A linguagem da realidade, enquanto era apenas natural, estava fora da nossa consciência: agora que surge "escrita" através do cinema, não pode deixar de encontrar-se com uma consciência. A linguagem escrita da realidade, far-nos-á saber, antes de tudo o mais, o que é a linguagem da realidade; e acabará por finalmente modificar o nosso pensamento diante dela, tornando as nossas relações físicas, pelo menos, com a realidade, relações culturais.Pier Paolo Pasolini, idem, pp. 191-192. E à página 167: "Na realidade, o cinema fazemo-lo vivendo, quer dizer existindo praticamente, quer dizer agindo. A vida toda no conjunto das suas acções é um cinema natural e vivo: nisso é linguisticamente o equivalente da língua oral, no seu momento natural ou biológico." 
ideologia visual complexa, alegórica, aberta a interpretações não determinativas, pluri-disciplinares. Estas interpretações, vistas como pontos significativos de uma alegoria do momento presente naquelas imagens, devem seguir o movimento da sua forma, e rastrear, na dispersão cronológica, suas origens.

Um diretor de televisão ou cinema tem à sua disposição uma iconografia e uma iconologia, um presente e um passado de imagens e histórias que surgirão no presente estético e cultural de suas produções. Desde a concepção do argumento até a finalização, um filme, um programa de $\mathrm{TV}$, envolvem em trabalho e ideologia, em forma artística e técnica, muitos profissionais e empresas, cujos nomes desfilam, atualmente, no seu fim, em listas intermináveis. Equipes menores ou enormes variam conforme as possibilidades econômicas e potencialidades artísticas, culturais e políticas de seus produtores.

Condicionadas por diferentes condições de locação, luminosidade, cenário, as filmagens também são planejadas em horas, dias. Seguem uma ordem planejada e, na maioria das vezes, não a ordem dos

\footnotetext{
${ }^{4}$ A origem, apesar de ser uma categoria totalmente histórica, não tem nada que ver com a gênese. $O$ termo origem não designa o vir-a-ser daquilo que se origina, e sim algo que emerge do vir-a-ser e da extinção. A origem se localiza no fluxo do vir-a-ser como um torvelinho, e arrasta em sua corrente o material produzido pela gênese. $O$ originário não se encontra nunca no mundo dos fatos brutos $e$ manifestos, e seu ritmo só se revela a uma visão dupla, que o reconhece, por um lado, como restauração e reprodução, e por outro lado, e por isso mesmo, como incompleto e inacabado. Em cada fenômeno de origem se determina a forma com a qual uma idéia se confronta com o mundo histórico, até que ela atinja a plenitude na totalidade de sua história. A origem, portanto, não se destaca dos fatos, mas se relaciona com sua pré e pós-história. Walter Benjamin - Origem do Drama Barroco Alemão, pp.67-68
}

acontecimentos que depois serão vistos na tela. As filmagens são feitas em pequenas seqüências, reordenadas (editadas) para a exibição ao público. Pequenos pedaços de tempo e de história emendados para compor uma nova narrativa, e portanto, uma nova visão histórica, uma ideologia visual em constante refazer.

Os produtos visuais mais populares apresentam-se na narração visual mais didática e clara, aquela que se vale da visão temporal cronológica, aparentemente natural $\mathrm{e}$ as pequenas inserções cronológicas de "cenas do passado" (flashbacks) são hoje perfeitamente inteligíveis. São narrações que tomam forma estética na representação visual que se movimenta em sequiências sustentadas pela razão cronológica, aproximando-se, pela sua verossimilhança naturalista espacial $\mathrm{e}$ temporal, à exposição de uma verdade.

A cronologia é o grau máximo do naturalismo no tempo. A própria observação dos seres, da natureza, durante um dia, um mês, anos, mostra esse tempo "natural", o ciclo do começo, desenvolvimento e fim, o passar do tempo. Ela, a cronologia, é a dimensão temporal de mais fácil entendimento. A sua hierarquia e sucessão inexoráveis são vistas como naturais e lógicas, e legitimam, em ideologia temporal, diferentes poderes. Quase como se a cronologia fosse a expressão objetiva do tempo político dominante. Não precisamos de esforço para perceber que a história oficial é sempre cronológica e os grupos que procuram ou se estabelecem no poder tentam criar, ao mesmo tempo, uma genealogia.

\footnotetext{
${ }^{5}$ Não utilizo aqui a tradicional discriminação entre narração e descrição. Já pouco sustentável para a interpretação literária, muito menos o é para a interpretação de imagens em movimento.
} 
Recontam, à sua maneira, as narrações anteriores, e produzem a sua própria narração em escrita e imagem, e, atualmente, principalmente em imagens.

É isso que vemos, por exemplo, nos programas da televisão, inclusive nos programas políticos ou nos filmes mais populares, mais fáceis, mais comerciais -uma narração cronológica, que constrói e reconstrói constantemente mitos e histórias. Personagens reais e ficcionais nascem, vivem e morrem em seus minutos de exibição. Aparecem em diferentes momentos e espaços de suas vidas. Expressam, em imagens e palavras, valores e mensagens diversas e participam, de diferentes maneiras, da grande construção mítica da sociedade contemporânea. Participam tanto da narração quanto como mostram-se como figuras morais e modelares de virtudes e vícios. Lugares, homens e mulheres reais

\footnotetext{
${ }^{6}$ A série das informações que um homem dá por si próprio enquanto realidade representando-se e agindo chama-se, por fim, exemplo: e esta é a diferença entre a linguagem da realidade natural e a da realidade humana. A primeira não dá mais do que informações, a segunda, ao mesmo tempo que as informações, dá o exemplo.

As técnicas audiovisuais captam o homem no momento em que este dá o exemplo (voluntariamente ou não). É por isso que a televisão é tão imoral. Porque não assentando em primeiro lugar sobre a montagem, limita-se a ser uma técnica audiovisual em estado puro, encontra-se, por conseguinte, muito próxima desse <<plano-seqüência >> ininterrupto que o cinema é virtualmente.

Os planos-seqüência da televisão mostram os homens de modo naturalista: fazem com que a sua realidade fale de acordo com o que é. Mas uma vez que a única intervenção não naturalista da televisão é o corte efetuado pela censura feita em nome da pequena burguesia, eis como o ecrã de TV se torna uma fonte perpétua de representação de exemplos de vida e de ideologia pequeno-burguesas. Ou seja de $<<$ bons exemplos >>. (...)

Se pode dizer-se que a realidade, enquanto representação de si própria, enquanto linguagem, é um <<cinema ao natural>>, pode afirmar-se igualmente que o cinema, reproduzindo-a, tornando-se a sua linguagem <<escrita〉>, põe em evidência o que ela é, sublinha a sua fenomenologia.
}

transcritos pela linguagem da televisão em signos da realidade. Dessa linguagem, que expressa a realidade com signos da própria realidade, decorre a credibilidade quase total do espectador naquilo que vê nas telas e que acredita ser real e verdade.

Daí a importância de interpretarmos as imagens do cinema e da televisão, e não somente as "populares", como expressões alegóricas do momento de sua produção e exibição. Alegorias em movimento. Eternizam-se a cada instante em que permanecem visíveis e enquanto resistem à deterioração e às restaurações. Alegorias do tempo presente e da história repassada nesse tempo presente.

As narrações visuais cronológicas são as mais populares desde há muito tempo e as mais eficazes politicamente. Se do ponto de vista dos produtores é importante manipular ou tentar controlar o entendimento dessas imagens, do ponto de vista da análise e da interpretação é importante entender não só o que estas narrações em imagens deixam ver, mas a linguagem de sua fabricação, o significado que essa linguagem atribui às "realidades" mostradas através da montagem das sequiências e cenas e aquilo que acontece entre elas. É a existência dessa montagem e do conseqüente intervalo entre as seqüências e cenas que faz, também, com que as pessoas saiam com sentimentos e opiniões muito diferentes, tendo assistido ao mesmo filme ou visto o mesmo programa de televisão. Intervalo que fica invisível nas emendas de cada seqüência que compõem uma narração em movimento visual.

$O$ cinema dá-nos, portanto, uma $<$ semiologia ao natural da realidade>>." (grifos do autor)

${ }^{7}$ O salto estabelecido pelo corte de uma imagem e sua substituição brusca por outra imagem, é um momento em que pode ser posta em xeque a "semelhança" da 
Os filmes e os programas de televisão são histórias entendidas como narrações e ao mesmo tempo celebrações visuais de modos de ver e estar no mundo que deixam ver e entrever diferentes mensagens existenciais, religiosas, políticas, morais. Imagens que são também mensagens. Mensagens que se configuram em formas e cores. Uma espécie catecismo visual.

Uma mensagem que se faz aparecer em formas plásticas, televisão ou no cinema, não é simplesmente uma mensagem retórica, que explicamos com palavras

representação frente ao mundo visível e, mais decisivamente ainda, é o momento de colapso da "objetividade" contida na indexalidade da imagem. Cada imagem em particular foi impressa na película, como conseqüência de um processo físico "objetivo", mas a justaposição de duas imagens é fruto de uma intervenção inegavelmente humana e, em princípio, não indica nada senão o ato de manipulação. Para os mais radicais na admissão de uma pretensa objetividade do registro cinematográfico, tendentes a minimizar o papel do sujeito no registro, a montagem será o lugar por excelência da perda de inocência. Por outro lado, a descontinuidade do corte poderá ser encarada como um afastamento frente a uma suposta continuidade de nossa percepção do espaço e do tempo na vida real (aqui estaria implicada uma ruptura com a semelhança). Veremos que tal "ruptura" é perfeitamente superada por um determinado método de montagem, com vantagens no que se refere ao efeito de identificação.

Para não nos confundir, chamemos a descontinuidade visual causada pela substituição de imagens de descontinuidade elementar. E lembremos que as alternativas de ação diante da montagem ocorrem esquematicamente em dois níveis articulados: (1) o da escolha do tipo de relação a ser estabelecida entre as imagens justapostas, que envolve o tipo de relação entre os fenômenos representados nestas imagens; esta escolha traz conseqüências que poderão ser trabalhadas num nível (2), o da opção entre buscar a neutralização da descontinuidade elementar ou buscar a ostentação desta descontinuidade.

Dependendo das opções realizadas diante destas alternativas, o "efeito de janela" e a fé no mundo da tela como um duplo do mundo real terá seu ponto de colapso ou de poderosa intensificação na operação de montagem. Ismail Xavier - $O$ Discurso Cinematográfico: A Opacidade e a Transparência, p. 17-18. destacadas da imagem que a configurou. Normalmente as pessoas explicam, verbalmente, a "mensagem" de um filme ou programa de televisão, como se a forma em que apareceu tivesse um sentido separado das palavras que a explicam. A interpretação deve ser verbal e visual ao mesmo tempo. Não deve contentar-se com explicações fechadas em teorias e irá buscá-las no universo interdisciplinar da cultura, da arte e da ciência.

\section{ANÁLISE}

O discurso televiso constitui a mais nova forma narrativa, ou talvez a mais antiga, na qual os gêneros tradicionais - a tragédia, a saga, a gesta, o auto, a moralidade, o sermão, a pregação, o drama, etc. - compõem um amalgama complexo com os modernos gêneros acadêmico, científico, político, publicitário, etc.

Diversas seqüências de programas de televisão serão vistas, agrupadas e analisadas como representativas do amplo Programa Visual ${ }^{8}$ do capitalismo que produz visões da realidade ao mesmo tempo que as transforma em objetos culturais e bens simbólicos. Visões transformadas em representações do real pelo meio televisão que lhes dá o estatuto de verdade. Essas representações visuais e sonoras são imagens e palavras que, ancoradas na memória do espectador, passam a constituir um repertório de "História e Verdade" com o qual ele

\footnotetext{
8 Programa Visual entendido como o conjunto de imagens, sons e palavras transmitidas pela televisão diariamente através das diferentes emissoras, tanto aquelas que operam em canais abertos como as que utilizam canais fechados e que compõe um discurso ideológico visual e sonoro.
} 
opina e age sobre a sociedade em que vive $^{2} .8$

Como se o capitalismo narrasse a si próprio em diferentes e dispersas aparições televisivas, através de seus personagens, burgueses e gestores, ao mesmo tempo, em que produzisse incessantemente sua história, como única e universal.

${ }^{9}$ Obs.: A proposta do projeto não é presa à idéia de audiência, nem à intenção de pesquisar um único canal de televisão, e tampouco restringir-se-á a um recorte cronológico seqüencial específico.

\section{Milton José de Almeida}

Prof. Dr. Faculdade de Educação /

UNICAMP

Coordenador do Laboratório de Estudos

Audiovisuais - OLHOFEUNICAMP

e-mail-mjose@correionet.com.br 